This item was submitted to Loughborough's Institutional Repository (https://dspace.lboro.ac.uk/) by the author and is made available under the following Creative Commons Licence conditions.

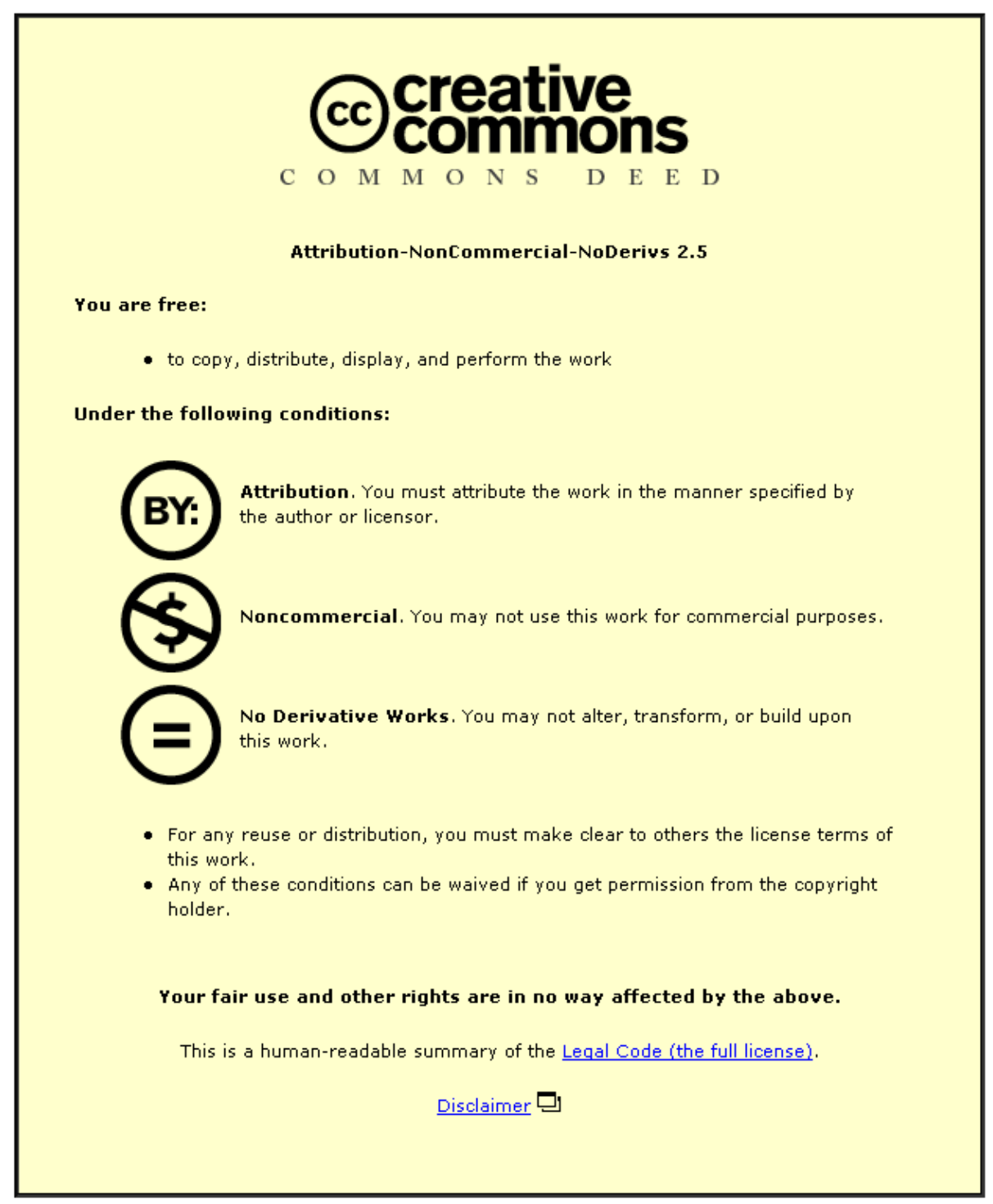

For the full text of this licence, please go to: http://creativecommons.org/licenses/by-nc-nd/2.5/ 


\section{Investigation into contractors' responsible sourcing implementation practice}

1 Jamie Young Design Manager, Morgan Sindall Construction, UK
2 Mohamed Osmani

Senior Lecturer, School of Civil and Building Engineering, Loughborough University, Loughborough, UK
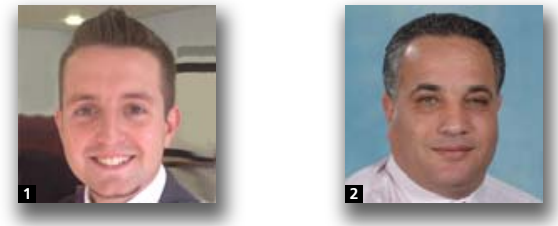

Over the last few years there has been an increasing demand for more efficient ways of procuring materials in terms of reducing their impacts on the environment. The UK Strategy for Sustainable Construction introduced a voluntary target of $\mathbf{2 5 \%}$ of all resources in the construction industry to be responsibly sourced by 2012 . At the time of writing there has been very limited research on responsible sourcing (RS), particularly in terms of contractors' current practices and implementation at project level. Therefore, an assessment of the current status of RS among the top 100 UK contractors has been captured using a questionnaire survey and follow-up interviews. The results indicate that no clear RS responsibility has been established, and there is no cohesive, top-down strategy from the strategic level (sustainability managers) to the implementation level (procurement mangers) in place in contracting companies. On the other hand, there was agreement that government leadership through the implementation of RS in all public projects could be a significant catalyst to drive RS in construction projects.

\section{Introduction}

Construction activities have a major impact on the environment through their consumption of resources, emissions of pollutants and generation of waste. The construction industry is by far the greatest consumer of resources of all industries in the UK and is the single largest contributor to greenhouse gases in the UK (Engineering and Physical Sciences Research Council, 2011). Defra (2006) argues that the construction industry needs to assess the impact that construction materials are having on global warming, particularly in terms of their manufacturing processes and transportation. The UK government, in partnership with the construction industry, published a Strategy for Sustainable Construction (SSC) in June 2008, which included a number of targets for responsible sourcing (RS) of materials and products. The SSC made a commitment to ensure that $25 \%$ of the products used in a construction project would be responsibly sourced by 2012 (BERR, 2008). The UK Contractors Group (UKCG) had initially developed an unprecedented stance on RS by putting even greater demands on its members' supply chains, requiring that $100 \%$ of products be responsibly sourced by 2015 . However, this target was later retracted and instead the UKCG has invited members to sign up to a new sustainable procurement policy that supports, and gives preference to, responsibly sourced materials, but does not set any targets against which RS can be measured (UKCG, 2012). Since 2008 two key RS schemes have been introduced in the UK: the Framework Standard for the Responsible Sourcing of Construction Products (BES 6001) (BRE, 2009) and the Responsible Sourcing Sector Certification Schemes for Construction Products (BS 8902) (BSI, 2009). BES 6001 provides guidance for construction product manufacturers to demonstrate a commitment to the RS of their materials and products. It requires companies to have quality management and supplier management systems in place and establish policies, objectives and metrics for environmental issues through quality management and supplier management systems. BS 8902, which focuses more specifically on bodies that certify construction products, provides requirements for the management, development, content and operation of sector certification schemes for RS and the supply of construction products.

The concept of RS has been introduced in the last decade in sectors such as the food and clothing industries through the 
development of statements of intent and purchasing practices. However, its application in the construction industry is in its infancy. Notwithstanding BES 6001 and BS 8902, which were designed specifically for the manufacturers of products and their supply industry, very little has been published on RS practice at a project level, particularly in terms of contractors' levels of knowledge and the current implementation status. By and large, the existing literature on RS in construction has been confined to a small number of academic publications, namely Glass (2011a), Glass et al. (2012) and Miller (2011). These publications have examined how RS sits in the construction industry's ever-growing sustainability agenda. However, no attempts have been made to investigate the extent to which RS is being routinely initiated and applied at project level by sustainability managers (SMs) and procurement managers (PMs) in the same contracting companies. This paper has, therefore, set out to capture contractors' assessment on RS drivers, their actual implementation status, and challenges and enablers from two organisational perspectives: the strategic level (SMs) and the implementation level (PMs).

\section{Context}

The literature reveals that there is no single definition of RS. BRE (2009) defines RS as

\footnotetext{
a holistic approach to managing a product from the point at which a material is mined or harvested in its raw state through manufacture and processing, through use, re-use and recycling, until its final disposal as waste with no further value.
}

They went further by stating that RS is demonstrated through a practice culture of 'supply chain management and product stewardship and encompasses social, economic and environmental dimensions'. On the other hand, the International Chamber of Commerce (ICC) describes RS in a more simplistic way as 'companies taking into account social and environmental considerations when managing relationships with suppliers' (ICC, 2008). Furthermore, the Action Programme on Responsible Sourcing (Apres, 2010) refers to RS as the management of sustainability issues associated with materials in the construction supply-chain, often from an ethical perspective'. Thus, existing RS definitions embrace a wide spectrum of sustainability issues covering a range of environmental, ethical, economic, social and life-cycle considerations.

Over the last decade there has been an increasing demand for more efficient ways of procuring materials in order to reduce their impact on the environment. Several drivers have been acting as catalysts to motivate RS uptake in the construction industry. These are discussed below.

There is strong support in the literature that procurement and RS are key processes to enhance sustainable project performance in construction projects (BERR, 2008; Defra, 2006,Defra, 2008). Osmani et al. (2008). Coventry et al. (2001) and Ekanayake and Ofori (2000) suggest that poor procurement practices can directly or indirectly generate construction waste. The literature on RS drivers focuses more on market gain and profit and less on the environmental impact of construction (Berry and McCarthy, 2011; Demaid and Quintas, 2006; Glass et al., 2011). Although RS targets set in the SSC are voluntary, the strategy should spark contractors to proactively select responsibly sourced materials and products, which in turn might trigger a new competitive paradigm. This is a view held by Berry and McCarthy (2011), BIS (2010) and Glass (2011a), who agreed that the SSC has had an inspiring effect on the development of RS. Defra (2006, 2007) acknowledge that, if the government is to make progress on its carbon targets, it should focus much more attention on carbon dioxide emissions from the production and transport of construction materials. The production and transport of materials are key parts of RS's action plan, which was the roadmap set out by the SSC to reach the RS targets, and, as such, need to be swiftly addressed (Cips, 2009; Wrap, 2010). From a legislative perspective, the Climate Change Act 2008 (2008), EU Emissions Trading Scheme (European Commission, 2008) and Site Waste Management Plans Regulations 2008 (HMG, 2008) (SWMPs) have all emphasised the importance of RS. However, only the latter has had a positive impact on sustainable project performance by driving waste reduction (CRWP, 2010; Envirowise, 2007; NetRegs, 2007). Paradoxically, Defra announced in March 2012 that the SWMPs Regulations are due to be scrapped as part of a red-tape cutting exercise and it has claimed that this will save UK businesses $£ 1$ billion (Defra, 2012). However, Constructing Excellence (2012) and the UK Green Building Council are among those opposing the move. This could act as a retrograde step on improvements in material resource efficiency on the one hand and inhibit RS uptake on the other.

\section{Current responsible sourcing implementation status}

$\mathrm{RS}$ in the construction industry is mainly judged through environmental assessment methods. However, there are two British Standards and other accreditation schemes that might need to be reviewed as RS becomes more embedded in current practices. These include BES 6001, which is seen as a key enabler that the government could use to reach its environmental goals (BSI, 2010; Glass, 2011b; Hughes, 2011). Ghumra et al. (2009) believe the BES 6001 was developed to address the imbalance between RS of different construction products while Glass (2011b) found that a significant number of construction stakeholders are finally becoming more aware of the existence of BES 6001 .

Breeam, the Council for Sustainable Homes (CSH) and Ceequal are the widely adopted environmental assessment 
Building Research Establishment environmental assessment method (Breeam)

Code for sustainable homes (CSH)

Civil engineering environmental quality assessment and award scheme (Ceequal)
A voluntary environmental assessment method and rating system for buildings. There are several different Breeam schemes available to assess different buildings ranging from offices and schools to health care and industrial buildings. Breeam assessment criteria are tailored to the type of building that is being assessed.

An environmental assessment method for rating and certifying the performance of new homes. It can be used to assess single dwellings as well as sites containing many houses and apartments. CSH awards new homes a rating from level 1 to level 6 against nine sustainability criteria.

An environmental assessment scheme for all types of civil engineering projects, including infrastructure, landscaping and public realm projects. Its aim is to demonstrate the commitment of the civil engineering industry to environmental quality and social performance. Examples of projects that can achieve Ceequal awards range from roads, bridges and airports to sports stadia, urban generation schemes and canals.

Table 1. Environmental assessment methods and their applications in construction projects

tools in the UK. Table 1 highlights the application of each these environmental assessment tools in construction projects.

Glass et al. (2011) stated that the knowledge of RS in Breeam by designers, contractors and product manufacturers is rather limited. They report that designers and contractors were concerned about the cost of securing RS credits in Breeamrelated projects. The $\mathrm{CSH}$ incorporates nine key sustainability components, including materials, into one policy. Osmani and O'Reilly (2009) argue that the CSH is among the most challenging and demanding international housing standards, although some believe it is not as effective and consistent as Breeam (McManus et al., 2010; National Planning Forum, 2010). RS makes up $7 \cdot 3 \%$ of the whole Ceequal assessment, which is more than that of Breeam $(5 \cdot 2 \%)$ and $\mathrm{CSH}(2 \cdot 7 \%)$. Although sustainability is widely embraced in building projects, Ceequal assessment offers more RS credit weighting than Breeam and $\mathrm{CSH}$.

\section{Responsible sourcing challenges and opportunities}

There is a consensus in the literature that a cultural change will lead to an increase in sustainable procurement and RS practice throughout the construction supply chain (Berry and McCarthy, 2011; Constructing Excellence, 2007; Defra, 2006). However, the biggest challenge is seen as the perceived cost of the implementation of RS (Forum for the Future, 2006; Walker, 2007). Conversely, Berry and McCarthy (2011) explained that the perceptions behind procuring responsibly sourced materials are flawed since sustainable procurement acts as a project life-cycle cost-cutting process. That said, current practice in the construction industry suggests that the primary emphasis of procurement is on short-term profitability
(Walker, 2007). This controversial duality comes down to a lack of knowledge and awareness of RS (Walker and Brammer, 2007), which is largely due to the infancy of the topic and the absence of a clear and common definition of RS (Glass, 2011b).

The literature reveals a lack of incentives, particularly financial, for companies to take on RS in their procurement policy and for their supply chain engagement (Defra, 2006; Forum for the Future, 2006; Riba, 2007). On the other hand, continuing improvements in sustainable project management have opened up a new green market in the construction industry, which could potentially incentivise construction stakeholders to implement RS in their projects (BERR, 2008) and allow product manufacturers to demonstrate their sustainable performance by certifying their products. Berry and McCarthy (2011) went further to argue that firms should be increasing their business through new sustainable products. Similarly, corporate social responsibility (CSR) enhancements have the potential to drive the uptake of RS (Glass et al., 2011; UCLU, 2010). This is supported by Wenblad (2001) who conducted a case study with Skanska and found that CSR was an essential part of a company's sustainability policy. Similarly, Glass et al. (2012) identified ethics and stakeholders as key components of sustainability and RS; however, the findings also revealed a lack of certainty on what CSR really entails.

\section{Research methodology}

A triangulated research methodology approach was adopted for this study, comprising a comprehensive literature review, a questionnaire survey and follow-up interviews. The Construction Index top $100 \mathrm{UK}$ contractors (Construction 
Index, 2011) was used as the source for the sampling frame for the questionnaire. The largest contracting companies were selected for the questionnaire survey because they have considerable and adequate resources in place, which should potentially facilitate the planning and implementation of RS in their projects. On individual levels, PMs and SMs were targeted for the survey, as both are involved in material sustainability and procurement in their organisations. In total, 200 questionnaires were sent out, 100 to PMs and 100 to SMs. Each contracting company was sent two questionnaires, one for the PM and the other for the SM. The aim of the questionnaire was to investigate the interpretation of $\mathrm{RS}$ in construction from the contractors' perspective at the organisational level and learn how this affects its implementation at project level. The questionnaire was based on results from a thorough literature review and all questions gave respondents the opportunity to add their qualitative views on drivers, barriers and incentives. The questionnaire results informed the design of an interview template and associated prompts. A semi-structured interview approach was adopted to provide the qualitative research for the study through eight interviews. The interview structure was followed in the same order for each interview, and probes were used at the end of key questions to fuel debate and generate comparative results. Interviews were conducted at a time that best suited the interviewees and usually took place in quiet locations where there were no interruptions.

The Statistical Package for Social Science (SPSS) 20.0.0 software was used to analyse the quantitative questionnaire data. The SPSS software facilitated the development of frequency distribution and statistic tables, capturing the overall mean response levels. The qualitative interviews were recorded first, which enabled full transcripts to be made, then coded into key themes and discussion points and finally analysed with the use of a matrix table. The analysis of the interviews followed a structured approach, with the analysis process concentrating on finding key themes and trends throughout the interviews.

\section{Data results and analysis}

The questionnaires yielded a mean response rate of $47 \%$. The follow-up interviews involved three PMs and five SMs. The findings from the questionnaire survey and interviews are discussed below.

\subsection{Responsible sourcing responsibility}

Over $60 \%$ and $30 \%$ of respondents reported that the responsibility for implementing sustainable procurement in their companies lies with PMs and SMs, respectively. Both questionnaire and interview respondents agreed that PMs are at present more involved with RS than SMs. However, all interviewees concurred that SMs are heavily involved in the process but mainly from a strategic perspective, as one interviewee pointed out: 'responsible sourcing is procurement based and as such sustainability managers' role is to set its agenda and procurement managers are responsible for its implementation'.

\subsection{Responsible sourcing in companies' policies and environmental assessment tools}

The respondent's views on the implementation of RS in environmental assessment methods and tools can be seen in Figure 1. Most of the participating contractors have RS embedded in their main sustainability policies. On the other hand, some participating PMs and SMs acknowledged that RS

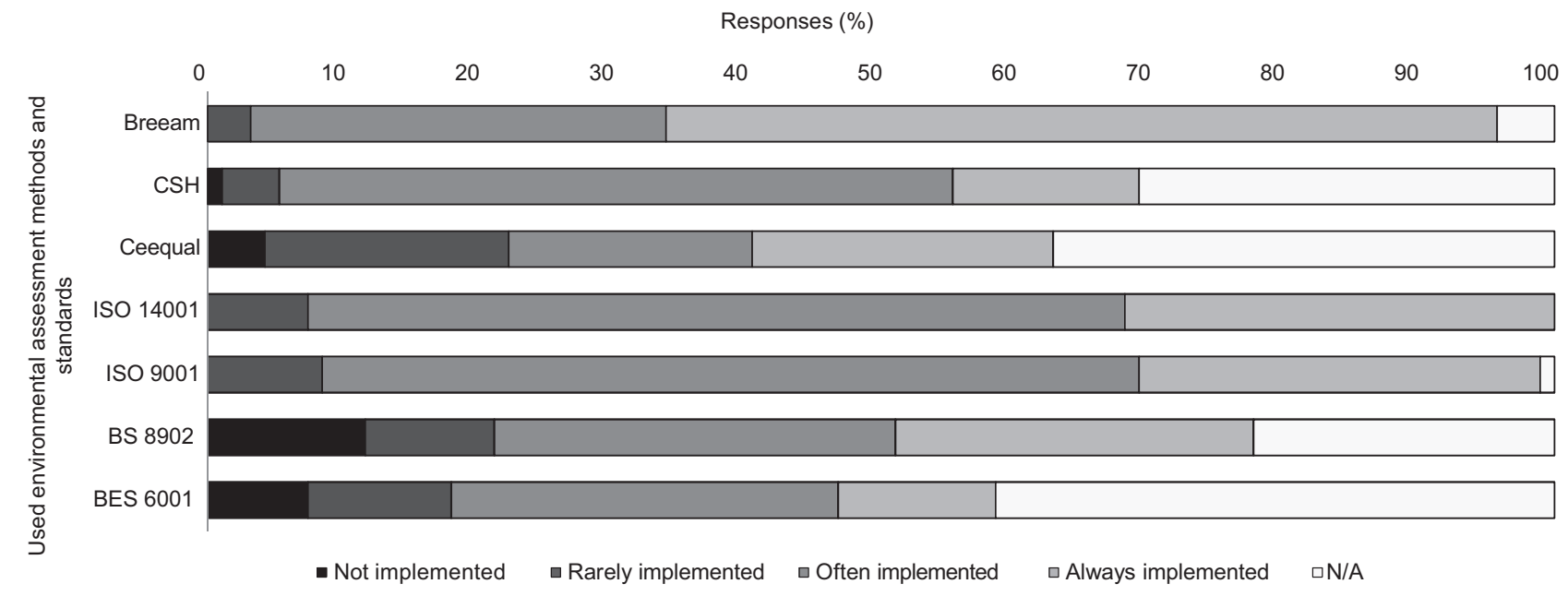

Figure 1. Contractors responsible sourcing implementation in environment assessment methods and standards (\%) 


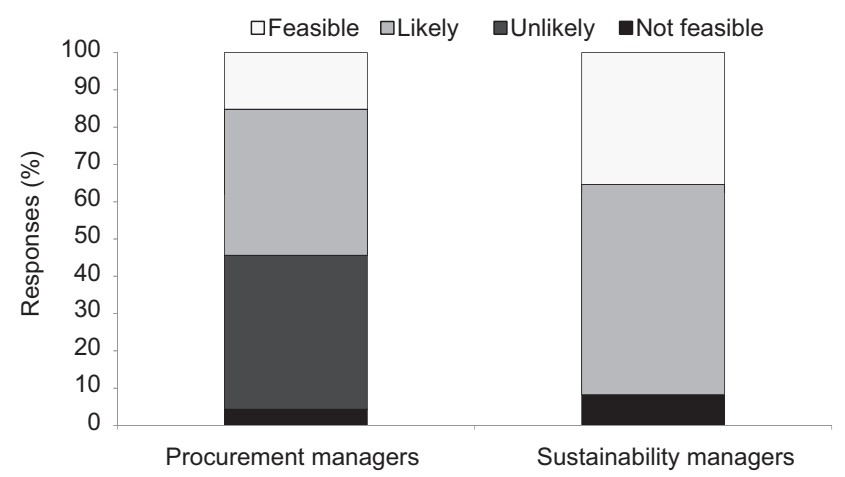

Figure 2. Procurement and sustainability managers' views on the feasibility of the Strategy for Sustainable Construction 2008 responsible sourcing target (25\% of products used in construction to be responsibly sourced by 2012)

is not embedded in CSR (14\%), waste minimisation (13\%) and procurement policies $(10 \%)$. Furthermore, only two of the eight interviewees stated that their respective company's sustainability policy includes a RS definition (see Figure 1).

Respondents were also asked about the extent to which RS is considered in environmental assessment tools in their current or recently completed projects. Results show that 62, 22 and $14 \%$ of respondents confirmed that RS is implemented in Breeam, Ceequal and CSH based projects, respectively. All interviewees explained that the relatively low RS implementation in Ceequal and CSH is mainly due to a lack of awareness across their supply chain, as noted by Glass et al. (2011).

\subsection{Responsible sourcing targets}

Respondents were asked about the practical feasibility of the government's 25\% RS target by 2012. As shown in Figure 2, more than $46 \%$ of responding PMs opined that this was not feasible; yet $90 \%$ of responding SMs claimed that the target would be reached. This conflicting perspective was raised during the interviews and both PMs and SMs interviewees respectively claimed that they were in a better position to comment on the feasibility of the targets than their counterpart. This again suggests a lack of a holistic RS approach and collaborative working at organisational level (see Figure 2).

\subsection{Responsible sourcing drivers}

The respondents were asked to rate drivers for RS in their current or recently completed projects using a 1 to 4 Likert scale $(1=$ not a driver; $4=$ major driver $)$. The results are shown in Figure 3; with the $y$ axis representing responses (mean values) and the $x$ axis showing the responsible sourcing drivers. Responding PMs identified three main RS drivers as being market gain and profit (3.37), CSR (3.22) and SSC $(3 \cdot 20)$. On the other hand, SMs identified the main RS drivers as CSR (3.54), clients' requirements (3.08) and the SSC (3.08). It was suggested during the interviews that the difference in the PMs and SMs response regarding drivers is due to their specific different job role focus. That said, all interviewees agreed that CSR has become one the key drivers to RS in their current projects (see Figure 3).

The largest difference in opinion came on the market gain and profit driver, which was rated by PMs as a significant or major driver $(3 \cdot 37)$, while SMs considered it to be less significant

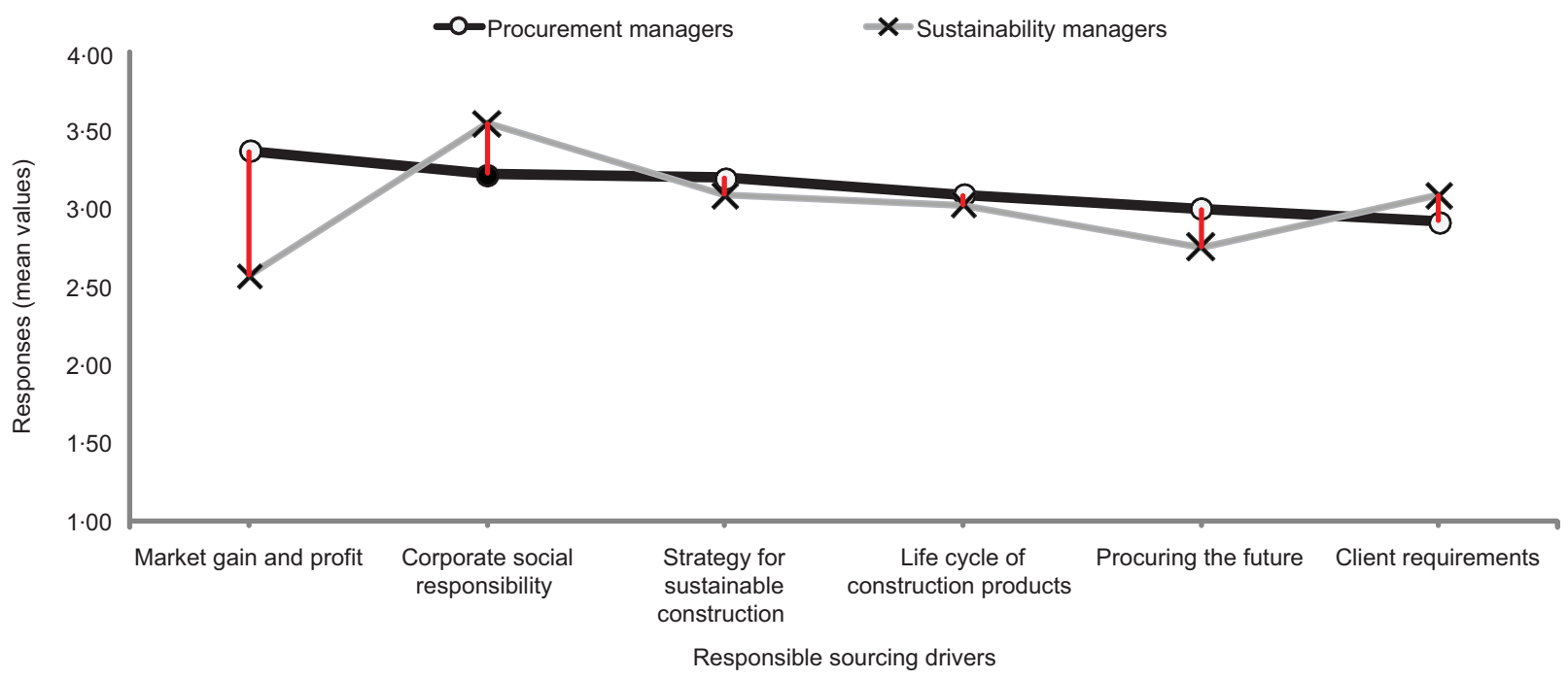

Figure 3. Responsible sourcing drivers in construction projects 


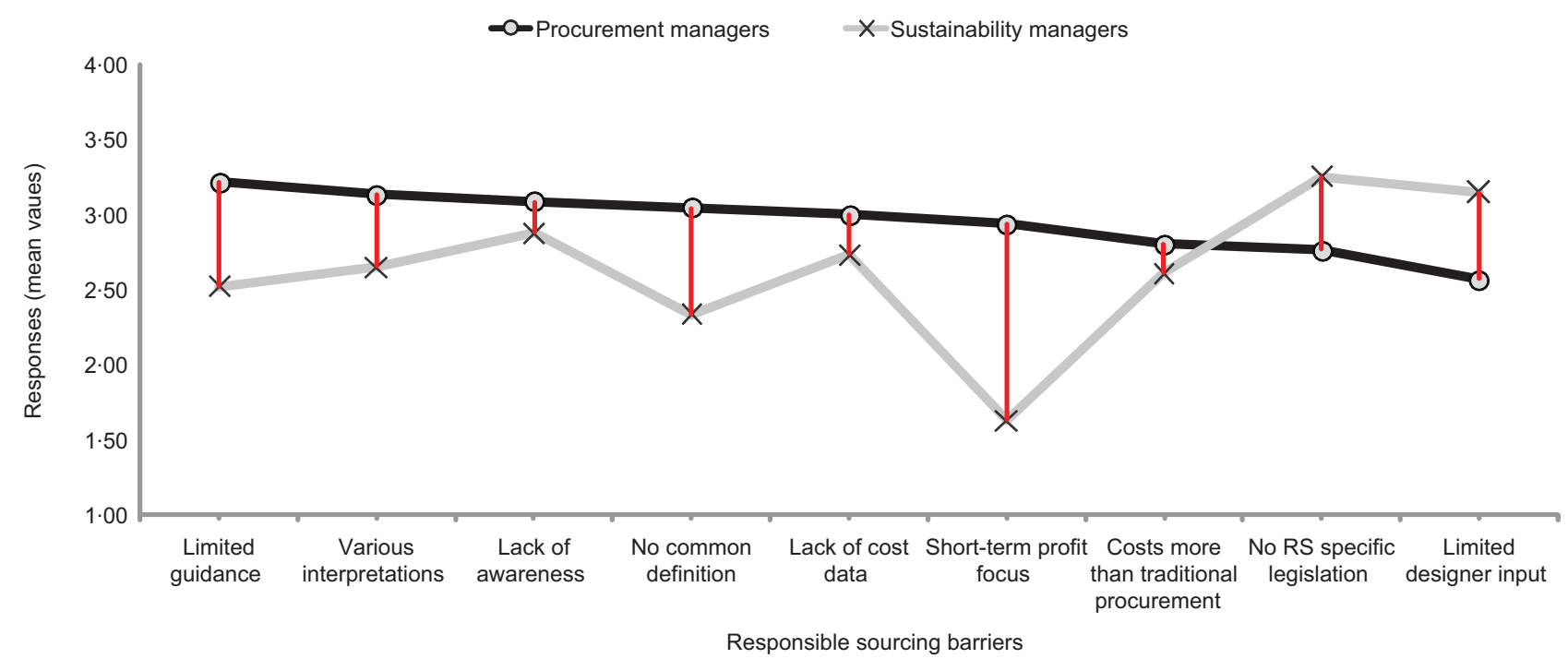

Figure 4. Responsible sourcing implementation barriers

(2.56). This was further discussed during the interviews, with the majority of both participants stating that PMs focus on project budget and, therefore, are not interested in sustainability, while SMs were more concerned with the environmental accreditations of materials than their cost implications. When probed on the impact of such divergence, most of the interviewees acknowledged that this difference in job specification focus could have a detrimental effect on RS implementation in their projects.

\subsection{Responsible sourcing barriers}

The respondents were asked to rate barriers to RS in their current projects or recently completed projects using a 1 to 4 Likert scale ( 1 = not a barrier; $4=$ major barrier $)$. The results are shown in Figure 4, with the $y$ axis representing responses (mean values) and the $x$ axis showing the responsible sourcing barriers. The top three barriers identified by responding PMs were limited guidance $(3 \cdot 22)$, various RS interpretations $(3 \cdot 13)$ and lack of awareness (3.09). However, SMs rated no specific RS legislation $(3 \cdot 25)$, limited RS input from designers $(3 \cdot 15)$ and lack of awareness of RS $(2 \cdot 88)$ as the main barriers. The results demonstrate a twofold challenge facing contractors to implement RS that need addressing: a government role to legislate, and industry and organisations' role to engage and educate their personnel and agree on a common RS definition.

The most notable conflicting view in relation to RS barriers between both sets of respondents relates to the focus on shortterm profit, which was rated by PMs as a significant barrier (2.93), while SMs recognised it as minor one (1.63). All interviewees agreed that this conflict of views stems from the divergence of educational background and job roles between
PMs and SMs. Equally, the rating of the lack of a common definition of RS barrier also produced some interesting findings, as it was deemed as a significant barrier $(3 \cdot 04)$ by PMs while it was thought to be an insignificant challenge $(2 \cdot 33)$ by SMs. This was also reiterated in the interviewees' responses. This difference was identified as being down to PMs needing a clear RS definition, as they were less conversant with RS than SMs (see Figure 4).

\subsection{Responsible sourcing incentives}

The respondents were asked to rate incentives that could drive the uptake of RS in their current and future projects using a 1 to 4 Likert scale ( $1=$ not an incentive; $4=$ major incentive). The results are shown in Figure 5, with the $y$ axis highlighting responses (mean values) and the $x$ axis showing the responsible sourcing incentives. The top three incentives identified by PMs were government leadership (3.52), financial rewards $(3 \cdot 30)$ and reducing tax on RS products $(3 \cdot 17)$. SMs identified government leadership $(3 \cdot 58)$, specific legislation on RS (3.46) and detailed guidance on RS-based procurement (3.00) as the main RS incentives. All interviewees agreed that government leadership through the implementation of RS in all public projects was the key to drive RS, while there was an ambiguous view about specific RS legislation, with a variety of answers being given. All interviewees claimed it would benefit RS, but most opined a similar view, that 'it was a sad state of affairs for the construction industry to need legislation to implement RS', as one SM interviewee put it (see Figure 5).

The idea of instigating financial rewards for reaching RS targets caused a major difference in opinion yet again, with PMs identifying it as their second most important incentive 


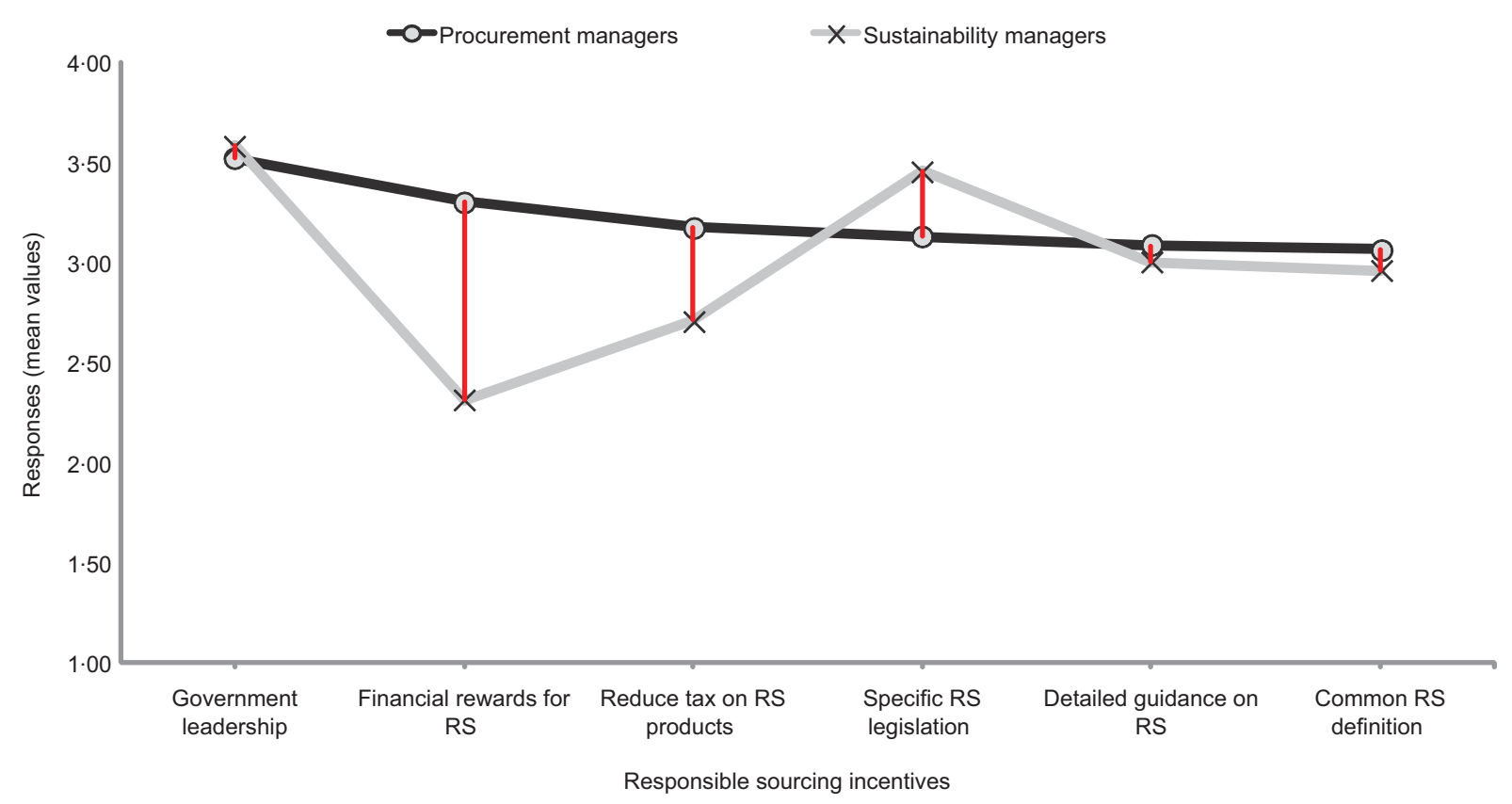

Figure 5. Responsible sourcing implemenation incentives

$(3 \cdot 30)$ while SMs identified it as their least important incentive (2.31). That said, all the interviewees suggested that PMs need financial incentives to justify buying sustainable over standard goods. Overall, the incentives highlighted by the questionnaire respondents and interviewees have the potential to kick-start RS appreciation and eventually its widespread uptake in the construction industry.

\section{Discussion}

The following section aims to identify and discuss trends and variations of the research findings in the literature. The key themes emanating from the research are discussed below.

\subsection{Feasibility of responsible sourcing targets}

The results reveal opposing views between participating PMs and SMs on the feasibility of the SSC 25\% RS target by 2012. Indeed, $90 \%$ of SMs were confident that the SSC target would be reached, yet $46 \%$ of PMs thought this was not feasible. This clear difference in opinion can only have a negative effect on the implementation of RS in the industry and was the first indicator that PMs and SMs see RS differently. This dual SMPM perspective on the achievability of the SSC $25 \%$ RS target by 2012 is absent from the literature.

\subsection{Driving the implementation of responsible sourcing}

The results show that sustainability is routinely built into current contractors' practice. However, respondents agreed that business and market drivers are the key promoters for RS. More specifically, business and ethical pressures are driving the implementation of RS, rather than sustainability principles. Ethical pressure plays its part in every business in terms of brand reputation. A company seen to be more ethical is more likely to attract ethically minded customers. This trend suggests that at present RS is being used for the purpose of financial gain and brand reputation, which is supported by Glass (2011b) and Miller (2011). Much of the early literature on RS suggests that sustainability, driven by climate change concerns, is one of the most important considerations for the construction industry (Addis and Talbot, 2001; DETR, 2000). However, recent studies have highlighted the cultural emphasis on business and profit-making sustainability practice (Berry and McCarthy, 2011). This is in line with the results of this research which indicates that, for contractors, sustainability has slipped down the business priority list. This might be a direct consequential result of the ongoing recession and the current economic climate.

\subsection{Barriers to responsible sourcing implementation}

There is a consensus in the literature that cost is the biggest single barrier to RS implementation in construction projects (Constructing Excellence, 2007; Forum for the Future, 2006; Walker and Brammer, 2007). This was supported by responding PMs who believed lack of data on cost implications and the focus on short-term profit are the major barriers to RS. Conversely, participating SMs believed that these are insignificant, which is in line with the findings of Glass et al. (2011) 
and Berry and McCarthy (2011). This explicit divergence of PMs' and SMs' views in the same contracting organisation is, in its own right, a major barrier to implementing RS. Furthermore, participating PMs and SMs reported that a lack of RS awareness at project, organisational and individual levels is a significant challenge to implementing $\mathrm{RS}$ in construction projects, a factor that was identified by Glass et al. (2011).

\subsection{Incentives to responsible sourcing implementation}

The results show that government leadership, reduced tax on RS products and specific RS legislation were deemed to be the main incentives to RS, which the existing literature has failed to identify. Furthermore, contrasting views between PMs and $\mathrm{SMs}$ on the impact of financial incentives to drive RS endorsement in construction projects highlight a disjointed organisational collaborative management strategy for RS.

\section{Conclusion}

This research set out to examine the current status of RS from the contractors' perspective. The data collection sampling population comprised SMs and PMs in the top $100 \mathrm{UK}$ contractors, who were targeted due to their pivotal involvement in sustainability and procurement practices in their own companies. Responding PMs and SMs had conflicting views on a number of critical RS issues, namely responsibility, challenges and incentives. Both groups of respondents claimed that these contrasting stances and evaluations were the result of job roles and educational backgrounds. The overall lack of awareness of RS is also a significant obstacle to its implementation, as very few clients state RS as a requirement in their project briefs and contractual documents. The results suggest that the government needs to take a leading role in implementing RS, by having all public projects include a RS implementation target that will inspire the industry. Equally, the UK construction industry needs to adopt a holistic approach towards RS by establishing an effective and allembracing RS collaborative management structure that has the potential to be a catalyst for the implementation of $\mathrm{RS}$ in the industry.

The current research agenda on RS is piecemeal and covers a wide range of issues covering generic RS awareness aspects; broad insights into stakeholders' familiarity with BES 6001 and BS 8902; its relation to environmental, economic, ethical and social considerations; how it should be demonstrated through sustainable procurement and CSR policies; supply chain engagement and RS credits in Breeam, CSH and Ceequal. However, there is a complete absence of research on the actual RS approach and implementation status by decision-makers for material sustainability (SMs) and material procurement (PMs) in contracting companies. As such, the research reported in this paper identified some critical findings related to divergent and in some cases contradictory RS perspectives. Indeed, the results suggest that no clear responsibility has been established for RS, and no cohesive top-down RS strategy from strategic level (SMs) to implementation level (PMs) is practised at the organisational level.

\subsection{Practical relevance}

This paper provides insights into contractors' current RS practice, challenges and enablers, which would greatly benefit both construction companies and researchers. Indeed, the findings will assist contractors in the formulation of collaborative and informed RS strategies. Similarly, results will instigate further research associated with RS implementation at organisational, project, and supply chain levels. Additionally, the findings could stimulate government's actions to drive RS uptake in construction projects through a combination of incentives and policies.

\section{Acknowledgements}

The authors sincerely thank all contracting companies and individuals who contributed to the research findings. Their time in completing the questionnaire survey and insightful participation and thorough engagement in the follow-up interviews are greatly appreciated.

\section{REFERENCES}

Addis B and Talbot R (2001) Sustainable Construction Procurement: a Guide to Delivering Environmentally

Responsible Projects. Construction Industry Research and Information Association, London, UK.

Apres (Action Programme on Responsible Sourcing) (2010) What is Responsible Sourcing? APRES, Loughborough University, Loughborough, UK. See http://apres.lboro.ac. uk/about.php (accessed 27/11/2012).

BERR (Business, Enterprise and Regulatory Reform) (2008) Strategy for Sustainable Construction 2008. BERR, London, UK.

Berry C and McCarthy S (2011) Guide to Sustainable Procurement. Construction Industry Research and Information Association, London, UK.

BIS (Department for Business, Innovation and Skills) (2010) Climate Change Adaptation Plan. BIS, London, UK. BRE (Building Research Establishment) (2009) BES 6001: ISSUE 2.0 Framework Standard for the Responsible Sourcing of Construction Products. BRE Environmental \& Sustainability Standard. BRE, London, UK.

BSI (2009) BS 8902:2009. Responsible sourcing sector certification schemes for construction products. BSI, London, UK.

Cips (Chartered Institute of Purchasing and Supply) (2009) Sustainable Procurement. Cips, London, UK.

Climate Change Act 2008 (2008) Elizabeth II. Her Majesty's Stationery Office, London, UK. 
Constructing Excellence (2007) Barriers to Sustainable Procurement in the Construction Industry. Construction Industry Research and Information Association, London, UK.

Constructing Excellence (2012) Constructing Excellence Position on Site Waste Management Plans. See http://www. constructingexcellence.org.uk/blog/?p=56 (accessed 24/04/ 2012).

Construction Index (2011) Top 100 Construction Companies. See http://www.theconstructionindex.co.uk/market-data/top100-construction-companies/2011 (accessed 15/01/2012).

Coventry S, Shorter B and Kingsley M (2001) Demonstrating waste minimisation benefits in construction. Construction Industry Research and Information Association, London, UK.

CRWP (Construction Resources and Waste Platform) (2010) Waste Minimisation across the Supply Chain: Areas to Focus on. CRWP, Liverpool, UK.

Defra (Department for Environment, Food and Rural Affairs) (2006) Procuring the Future: Sustainable Procurement National Action Plan: Recommendations from the Sustainable Procurement Task Force. Defra, London, UK.

Defra (2007) Waste Strategy for England 2007. Defra, London, UK.

Defra (2008) Progress Report on Sustainable Products and Materials. Defra, London, UK.

Defra (2012) Red Tape Challenge: Environment Theme Challenge Implementation. Defra, London, UK.

Demaid A and Quintas P (2006) Knowledge across cultures in the construction industry: sustainability, innovation and design. Technovation 26(5-6): 603-610.

DETR (Department for Environment, Transport and the Regions) (2000) Building a better quality of life: a strategy for more sustainable construction. DETR, London, UK.

EC (European Commission) (2008) The EU Emissions Trading Scheme. European Commission, Brussels.

Ekanayake L and Ofori G (2000) Construction material waste source evaluation. In Proceedings of the International Conference on Strategies for a Sustainable Built Environment, Pretoria.

Engineering and Physical Sciences Research Council (2011) Built Environment. See http://www.epsrc.ac.uk/pages/default. aspx (accessed 01/09/2011).

Envirowise (2007) An Introduction to Site Management Plans. Waste and Resources Action Programme, Banbury, UK.

Forum for the Future (2006) Sustainable Procurement Task Force: Survey of Procurement Professionals. Defra, London, UK.

Ghumra S, Watkins M, Philips P, Frost MW and Anderson J (2009) Developing an LCA-based tool for infrastructure projects. Proceedings of 25th Annual Conference of Association of
Researchers in Construction Management ARCOM, Nottingham, UK, pp.1003-1010.

Glass J (2011a) Briefing: responsible sourcing of construction products. Proceedings of the Institution of Civil Engineers: Engineering Sustainability 164(3): 164-165, http://dx.doi. org/10.1680/ensu.1000011.

Glass J (2011b) Responsible sourcing in construction products: can anything be learned from 'fair trade' schemes? Proceedings of Corporate Responsibility Research Conference 2011, Leeds, UK.

Glass J, Achour N, Parry T and Nicholson T (2011) The role of responsible sourcing in creating a sustainable construction supply-chain. Proceedings of the CIB International Conference Management and Innovation for a Sustainable Built Environment MISBE2011, Amsterdam, The Netherlands.

Glass J, Achour N, Parry T and Nicholson T (2012) Engaging small firms in sustainable supply chains: responsible sourcing practices in the UK construction industry. International Journal of Agile Systems and Management 5(1): 29-58.

HMG (Her Majesty's Government) (2008) Site Waste Management Plans Regulations 2008. The Stationery Office, London, UK.

Hughes D (2011) The BES 6001 framework standard for the responsible sourcing of construction products. Proceedings of APRES Conference, Loughborough University, Loughborough, UK.

ICC (International Chamber of Commerce) (2008) ICC Guide to Responsible Sourcing. ICC Commission on Business in Society, Paris, France.

McManus A, Gaterell M and Coates L (2010) The potential of the Code for Sustainable Homes to deliver genuine 'sustainable energy' in the UK social housing sector. Energy Policy 38(4): 2013-2019.

Miller F (2011) Responsible sourcing: meeting the strategic forum for construction's 2012 target, Proceedings of APRES Conference, Loughborough University, Loughborough, UK.

National Planning Forum (2010) Improving the Connection. Proposals from the National Planning and Building Control Working Group, London, UK.

NetRegs (2007) Site Waste - It's Criminal: a Simple Guide to Site Waste Management Plans. NetRegs, Bristol, UK.

Osmani M and O'Reilly A (2009) Feasibility of zero carbon homes in England by 2016: A house builder's perspective. Building and Environment 44(9): 1917-1924.

Osmani M, Glass J and Price AD (2008) Architects perspectives on construction waste minimisation by design. Waste Management 28(7): 1147-1158.

Riba (Royal Institute of British Architects) (2007) Draft Strategy for Sustainable Construction. Riba, London, UK.

UCLU (University College London Union) (2010) Sustainable Procurement Review. UCLU, London, UK. 
UKCG (UK Contractors Group) (2012) UKCG Statement on the Procurement of Materials. UKCG. See http://www.ukcg.org. uk/media-centre/single/v/ukcg-statement-on-theprocurement-of-materials-1/ (accessed 25/04/2012).

Walker H (2007) Successful Business and Procurement Review: What Lessons for Sustainable Public Procurement can be Drawn from Successful Businesses? University of Bath: School of Management, Bath, UK.
Walker H and Brammer S (2007) Sustainable Procurement in the United Kingdom Public Sector. University of Bath: School of Management, Bath, UK.

Wenblad A (2001) Sustainability in the construction business a case study, Corporate Environmental Strategy 8(2): 157164.

WRAP (2010) The Drivers. See http://aggregain.wrap.org.uk/ procurement/benefits/drivers.html (accessed 26/11/2011).

\section{WHAT DO YOU THINK?}

To discuss this paper, please email up to 500 words to the editor at journals@ice.org.uk. Your contribution will be forwarded to the author(s) for a reply and, if considered appropriate by the editorial panel, will be published as discussion in a future issue of the journal.

Proceedings journals rely entirely on contributions sent in by civil engineering professionals, academics and students. Papers should be 2000-5000 words long (briefing papers should be 1000-2000 words long), with adequate illustrations and references. You can submit your paper online via www.icevirtuallibrary.com/content/journals, where you will also find detailed author guidelines. 